\title{
Bartonella Henselae endocarditis mimicking ANCA associated vasculitis
}

\author{
Sunita Paudyal ${ }^{1}$, Daniel T Kleven², Alyce M Oliver*3 \\ ${ }^{1}$ Department of Medicine, Medical College of Georgia, USA \\ ${ }^{2}$ Department of Pathology, Medical College of Georgia, USA \\ ${ }^{3}$ Division of Rheumatology, Allergy and Adult Immunology, Department of Medicine, Medical College of Georgia, USA
}

Received: March 10, 2016

DOI: $10.5430 /$ crim.v3n2p29
Accepted: March 28, $2016 \quad$ Online Published: April 14, 2016

URL: http://dx.doi.org/10.5430/crim.v3n2p29

\begin{abstract}
Bartonella can cause a damaging endocarditis and patients typically need valve replacement. Infective endocarditis (IE) and small vessel vasculitis (SVV) can have similar clinical features and the presence of ANCA can be misleading and it is critical to differentiate between IE and SVV since their treatment are vastly different.
\end{abstract}

Key Words: ANCA, Vasculitis, Bartonella, Glomerulonephritis, Endocarditis

\section{INTRODUCTION}

Bartonella species are fastidious, gram negative rods, initially isolated in 1988. ${ }^{[1]}$ The first case of Bartonella endocarditis was published in $1993^{[2]}$ and accounts for $3 \%$ of all cases of infective endocarditis (IE) ${ }^{[3]}$ but is the second most common (28\%) cause of culture negative IE after Coxiella burnetti. ${ }^{[4,5]}$ Of the 23 species identified, more than 14 causes zoonotic disease with arthropod vectors. ${ }^{[4]}$ Bartonella henselae infection is a zoonotic disease with cats as the most important reservoir. It is the etiological agent of cat scratch disease, although transmission to humans does not always require being scratched by a cat. ${ }^{[6]}$ ANCA (anti neutrophil cytoplasmic antibody) are typically associated with small vessel vasculitis (SVV), however they can also be present in patients with IE. ${ }^{[7]}$ Since both can be ANCA positive and have similar signs and symptoms, it is crucial to differentiate between these two entities.

\section{CASE REPORT}

A 42-year-old white female with no significant past medical history presented with intermittent fevers up to $39^{\circ} \mathrm{C}$ associated with chills for two months which would improve with nonsteroidal agents and acetaminophen. Family history was significant for a sister with mitral valve replacement at a young age, details of which were not clear. Social history was significant for remote history of intravenous drug use (cocaine, methamphetamine) and half pack a day smoking. She also lived on a farm and was exposed to various animals including dogs, cats and chickens. Review of systems was notable for a 30 pound weight loss over the course of two months along with loss of appetite, nausea and bilateral inner thigh rash three weeks prior to presentation. She endorsed some generalized hair thinning, headaches, as well as burning sensation of hands and feet. Upon examination she was febrile with a temp of $38^{\circ} \mathrm{C}$, blood pressure was 156/96 $\mathrm{mmHg}$, pulse was $80 \mathrm{bpm}$. Besides having several tattoos over both arms her exam was unremarkable including no

\footnotetext{
* Correspondence: Alyce M Oliver, Associate Professor; Email: aloliver@gru.edu; Address: Department of Medicine, Division of Rheumatology, Allergy and Adult Immunology, Medical College of Georgia, USA.
}

Published by Sciedu Press 
murmurs on auscultation and no rashes.

Initial labs showed WBC $3.5 \times 10^{3}\left(4.5-11 \times 10 / \mathrm{mm}^{3}\right)$, Hemoglobin $6.1 \mathrm{~g} / \mathrm{dl} 12-16 \mathrm{mg} / \mathrm{dl}$, Platelets $145 \times 10^{3}(150$ $\left.400 \times 10^{3} / \mathrm{mm}^{3}\right)$, MCV $78.1 \mathrm{fL}$ ( 80-98 fL), ESR $34 \mathrm{~mm} / \mathrm{hr}$ $(0-19 \mathrm{~mm} / \mathrm{hr})$, creatinine $2.29 \mathrm{mg} / \mathrm{dl}(0.6-1.60 \mathrm{mg} / \mathrm{dl})$, with the rest of the metabolic parameters being within normal range. Urinalysis was notable for many RBCs, no casts, urine protein was $91 \mathrm{mg} / \mathrm{dl}$ and urine creatinine $73 \mathrm{mg} / \mathrm{dl}$ (ratio 1.3). A urine drug screen was negative. ANA was positive with 1:80 titer, homogenous, and 1:160 titer, speckled. C3 was low at $76 \mathrm{mg} / \mathrm{dl}(90-170 \mathrm{mg} / \mathrm{dl})$ and C4 was normal at $17 \mathrm{mg} / \mathrm{dl}(12-36 \mathrm{mg} / \mathrm{dl})$. Rheumatoid factor was $18 \mathrm{IU} / \mathrm{ml}$ (< $14 \mathrm{IU} / \mathrm{ml})$, ASO titer was $152 \mathrm{U}(0-530 \mathrm{U})$. Both C-ANCA and P-ANCA were positive with PR3 of $0.5 \mathrm{U}(<$ $0.4 \mathrm{U})$ and $\mathrm{MPO}$ of $1.8 \mathrm{U}(<0.4 \mathrm{U})$. Blood and urine cultures again did not show any growth. A hepatitis panel and HIV test were also negative. A CT chest was unremarkable. A transesophageal echocardiogram (TEE) demonstrated thickened tricuspid valve with small vegetation with a hooded appearance which was consistent with myxomatous degeneration. Ejection fraction was 55\%-60\%. Renal US showed mildly echogenic kidneys and minimal left hydronephrosis A renal biopsy was obtained which showed immune complex mediated focal proliferative glomerulonephritis that was not suggestive of any specific etiology. Immunofluorescence staining demonstrating extensive immune complex deposition that would be classic for lupus was not seen, however more deposition was present than would be seen in an ANCA associated pauci-immune glomerulonephritis. Under electron microscopy classic subepithelial humps that characterize infection were not seen although $\mathrm{C} 3$ and $\mathrm{C} 1 \mathrm{q}$ were dominant. A diagnosis of a non specific immune complex mediated vasculitis was made and she was treated initially with high dose oral prednisone that improved her fevers as well as renal function.

However, repeatedly, as the prednisone was tapered to below $20 \mathrm{mg}$ her fevers returned and she developed a vasculitic rash over bilateral lower extremities as well as bilateral MCP arthralgias, 1-2 hours of morning stiffness and requiring readmission. A repeat transthoracic echocardiogram did not show any vegetations, and with a higher dose of prednisone her symptoms again resolved. Patient continued to show significant hematuria. At this point Bartonella titers were obtained and B. henselae $\operatorname{IgG}:>1: 1024$, B.quintana IgG titers 1:512. A repeat transesophageal echocardiogram (TEE) showed large partially calcified vegetations in two out of three valves in the tricuspid valve with significant valvular damage and moderate tricuspid regurgitation. She was then urgently referred to CT surgery and was admitted for tricuspid valve replacement and started on ceftriaxone, doxycycline, and gentamicin. Tricuspid valve Steiner stain showed rare rod shaped organisms consistent with Bartonella (see Figure 1). The valve PCR later came back positive for Bartonella.

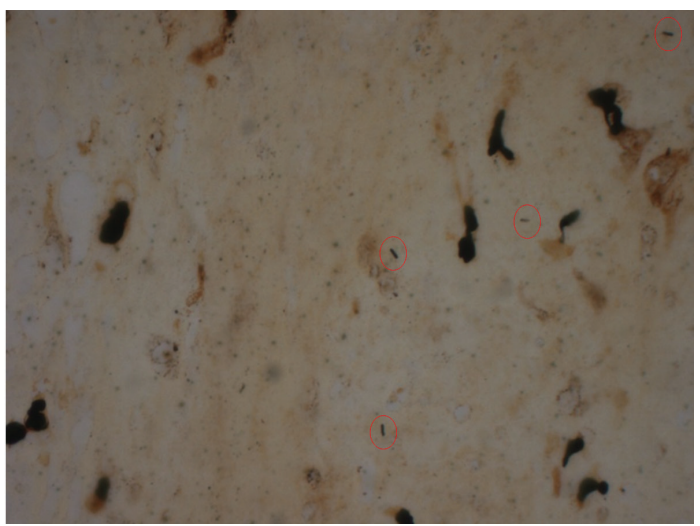

Figure 1. Steiner stain of aortic valve demonstrating rare rod shaped organisms (ovals) consistent with Bartonella

\section{REVIEW}

The patient discussed above posed a significant diagnostic challenge, supporting the fact that Bartonella endocarditis is grossly under recognized. It has a subacute, nonspecific presentation especially with asthenia and weight loss; and may also have embolic phenomenon, immune complex glomerulonephritis, rash consistent with $\mathrm{SVV}^{[8]}$ and ANCA positivity. Furthermore initial infectious workup can be unrevealing.

In a published series from France $B$. henselae endocarditis was found to be associated with underlying valvular pathology ${ }^{[4]}$ particularly involving the left sided valves, and most patients with Bartonella endocarditis had extensive valve damage requiring surgery. ${ }^{[4]}$ Our patient did not have documented valvular damage, but may have had a damaged valve from previous IVDU or changes since birth as her sister also had received a valve replacement. Bartonella has a predilection for native aortic valve. ${ }^{[9,10]}$ There are 2 other published cases of native tricuspid valve endocarditis. ${ }^{[11,12]}$ Left sided endocarditis remains most common but right sided valves may be affected by Bartonella as in our patient. Reports in the literature demonstrate high levels of C-ANCA and less commonly p-ANCA, or both. ${ }^{[13]}$ In fact there are several reports of Bartonella IE that were masquerading as vasculitis. ${ }^{[7,10]}$ Although the prevalence of ANCA in all cause IE was $18 \%$ (total 109 patients), ${ }^{[13]}$ Bartonella IE, in particular, appears to be associated with a much higher rate of ANCA positivity in up to $60 \%{ }^{[14]}$ in a recently published case series comprising of 47 patients. There are several hypotheses as to why PR3 antibody are induced during infection including presence of superantigens and molecular mimicry. ${ }^{[15]}$ At present there are no guidelines for diagnosis of Bartonella IE 
with only up to $20 \%$ with positive blood cultures. ${ }^{[4]}$ Positive PCR from cardiac valve or blood specimen, and IgG titer of $>/=1: 800$ have been recommended for diagnosis, and suggested to be included as a major Duke criteria by some investigators. ${ }^{[4]}$

In conclusion, IE and SVV can have a similar clinical spectrum including fevers, malaise, arthralgia, rash, renal disease, and valvular involvment. However, suspicion for infective endocarditis should include dual ANCA positivity and, low $\mathrm{C}^{[7]}$ as SVV typically do not have low complements. Culture negative causes of IE including Bartonella must be pursued in the presence of ANCA positivity in the appropriate clinical setting.

\section{CONFlicts of InTEREST Disclosure}

The authors have declared no conflicts of interest.

\section{REFERENCES}

[1] English CK, Wear DJ, Margileth AM, et al. Cat-scratch disease. Isolation and culture of the bacterial agent. Jama. 1988; 259(9): 1347-52. PMid:3339840 http://dx.doi.org/10.1001/jama.1988.037 20090037031

[2] Spach DH, Callis KP, Paauw DS, et al. Endocarditis caused by Rochalimaea quintana in a patient infected with human immunodeficiency virus. Journal of Clinical Microbiology. 1993; 31(3): 692-4. PMid:8458964

[3] Raoult D, Fournier PE, Drancourt M, et al. Diagnosis of 22 new cases of Bartonella endocarditis. Annals of Internal Medicine. 1996; 125(8): 646-52. PMid:8849149 http://dx.doi.org/10.7326/0 003-4819-125-8-199610150-00004

[4] Edouard S, Nabet C, Lepidi H, et al. Bartonella, a common cause of endocarditis: a report on 106 cases and review. Journal of Clinical Microbiology. 2015; 53(3): 824-9. PMid:25540398 http: //dx.doi.org/10.1128/JCM.02827-14

[5] Houpikian P, Raoult D. Blood culture-negative endocarditis in a reference center: etiologic diagnosis of 348 cases. Medicine. 2005; 84(3): 162-73. PMid:15879906 http://dx.doi.org/10.1097/0 1.md.0000165658.82869.17

[6] Akiyama Y, Sakurai Y, Kato Y, et al. Retrospective study of salazosulfapyridine in eight patients with rheumatoid arthritis on hemodialysis. Modern rheumatology / the Japan Rheumatism Association. 2014; 24(2): 285-90. PMid:24252022 http://dx.doi .org/10.3109/1 4397595. 2013.843746

[7] Robert SC, Forbes SH, Soleimanian S, et al. Complements do not lie. BMJ Case Reports. 2011; 2011.

[8] Sugiyama H, Sahara M, Imai Y, et al. Infective endocarditis by Bartonella quintana masquerading as antineutrophil cytoplasmic antibody-associated small vessel vasculitis. Cardiology. 2009; 114(3):
208-11. PMid:19602882 http://dx.doi.org/10.1159/00022 8645

[9] Fournier PE, Lelievre H, Eykyn SJ, et al. Epidemiologic and clinical characteristics of Bartonella quintana and Bartonella henselae endocarditis: a study of 48 patients. Medicine. 2001; 80(4): 245-51. PMid:11470985 http://dx.doi.org/10.1097/00005792-200 107000-00003

[10] Teoh LS, Hart HH, Soh MC, et al. Bartonella henselae aortic valve endocarditis mimicking systemic vasculitis. BMJ Case Reports. 2010; 2010. PMid:9817529 http: //dx.doi .org/10 . 1080/003655498 50160783

[11] Bruneel F, D'Estanque J, Fournier PE, et al. Isolated right-sided Bartonella quintana endocarditis in an immunocompetent adult. Scandinavian Journal of Infectious Diseases. 1998; 30(4): 424-5.

[12] Verdier-Watts F, Peloni JM, Piegay F, et al. An exceptional case of tricuspid infective endocarditis due to Bartonella henseale revealed by an old pulmonary embolism. Annales de cardiologie et d'angeiologie. 2015.

[13] Mahr A, Batteux F, Tubiana S, et al. Brief report: prevalence of antineutrophil cytoplasmic antibodies in infective endocarditis Arthritis \& Rheumatology. 2014; 66(6): 1672-7. PMid:24497495 http://dx.doi.org/10.1002/art.38389

[14] Aslangul E, Goulvestre C, Mallat Z, et al. Human bartonella infective endocarditis is associated with high frequency of antiproteinase 3 antibodies. The Journal of Rheumatology. 2014; 41(2): 408-10. PMid:24488854 http://dx.doi.org/10.3899/jrheum. 130150

[15] Jennette JC, Falk RJ, Gasim AH. Pathogenesis of antineutrophil cytoplasmic autoantibody vasculitis. Current Opinion in Nephrology and Hypertension. 2011; 20(3): 263-70. PMid:21422922 http: //dx.doi.org/10.1097/MNH.0b013e3283456731 